\title{
ARTICLE
}

\section{Characterization of the VULCANO test products for fuel debris removal from the Fukushima Daiichi Nuclear Power Plant}

\author{
Toru Kitagaki ${ }^{\mathrm{a}, b^{*}}$, Hirotomo Ikeuchi ${ }^{\mathrm{a}, \mathrm{b}}$, Kimihiko Yano ${ }^{\mathrm{a}, \mathrm{b}}$, Hideki Ogino ${ }^{\mathrm{a}, \mathrm{b}}$, Jean-François Haquet ${ }^{\mathrm{c}}$, Laurent Brissonneau ${ }^{\mathrm{c}}$, \\ Brigitte Tormos $^{\mathrm{c}}$, Pascal Piluso ${ }^{\mathrm{c}}$ and Tadahiro Washiya ${ }^{\mathrm{a}, \mathrm{b}}$,

\begin{abstract}
${ }^{a} J a p a n$ Atomic Energy Agency, 4-33 Muramatsu, Tokai-mura, Naka-gun, Ibaraki-ken, 319-1194, Japan; ${ }^{b}$ International Research Institute for Nuclear Decommissioning, 2-23-1 Nishi-Shimbashi, Minato-ku, Tokyo, 105-0003, Japan; ' Commissariat à l'énergie atomique et aux énergies alternatives, Saint-Paul Lez Durance, 13108, France
\end{abstract}

\begin{abstract}
The characteristics of fuel debris are required to develop tools to remove it from severely damaged nuclear power plants, but the knowledge on molten core concrete interaction (MCCI) product is limited. The VULCANO MCCI test campaign, VBS-U4, was selected for the analysis as the conditions are similar to MCCI at Fukushima daiichi nuclear power plant. Physicochemical phenomena during MCCI were estimated from the macrostructure of the samples. Moreover, heterogeneous microstructure of the oxide region and homogeneous microstructure of the metallic region was confirmed. Additionally, the obvious difference of Vickers hardness between oxide and metallic phase is evaluated.
\end{abstract}

Keywords: bremsstrahlung; Fukushima Daiichi Nuclear Power Plant; MCCI; fuel debris; mechanical properties; hardness; phase; decommissioning; severe accident

\section{Introduction}

Fuel debris removal is one of the most important processes for decommissioning a severely damaged nuclear power plant (NPP) such as the Three Mile Islands nuclear generating station (TMI-2) and Fukushima daiichi NPP (1F). The characteristics of fuel debris are required to develop fuel debris removal tools [1]. In case of $1 \mathrm{~F}$, molten core concrete interaction (MCCI) would occur in the primary containment vessel, and the reaction product would be produced. Although the characteristics of the MCCI product generated under $1 \mathrm{~F}$ condition should be evaluated, our limited knowledge hampers it. Because there was no MCCI at the TMI-2 accident, and most of the damaged fuel in Chernobyl NPP remains without removal from the reactor building. Moreover, previous researches on severe accidents pertaining to MCCI were mainly focused on the concrete ablation phenomena for a safety assessment of the NPP. Although some MCCI test products have been analyzed, only the structure at the millimeter and centimeter scale was reported from the viewpoint of MCCI progression $[2,3]$. Additionally, the phase and microstructure of corium-spreading test materials at the micrometer scale is analyzed, but the characteristics differ somewhat from an MCCI product [4].

It is assumed that the test products generated in the

*Corresponding author. Email: kitagaki.toru@jaea.go.jp
MCCI experiments under similar conditions to $1 \mathrm{~F}$ have similar characteristics to that encountered in actual $1 \mathrm{~F}$ MCCI products. VULCANO MCCI test campaigns have been performed under several conditions by CEA. In this study, the VULCANO test campaign under similar conditions such as concrete ablation ratio to $1 \mathrm{~F}$ was selected. The test samples were then characterized.

\section{Test campaign selection}

\subsection{Initial test conditions}

Characteristics of the MCCI product depends on initial corium and concrete composition since the MCCI product is composed of corium and concrete components. Initial test conditions of past VULCANO test campaigns were compared with that of the $1 \mathrm{~F}$ as shown in Figure 1. Several VULCANO MCCI tests have similar conditions to $1 \mathrm{~F} 1$.

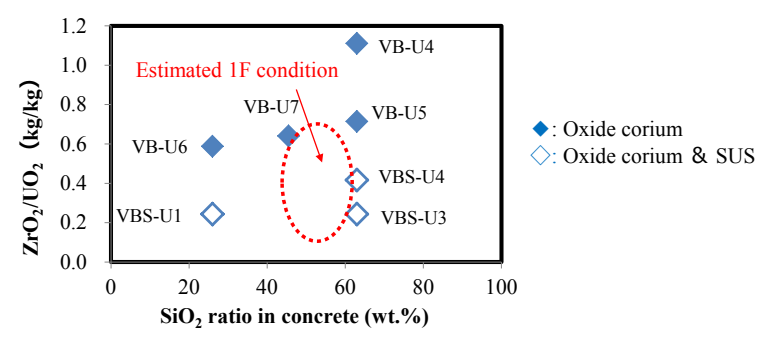

Figure 1. Initial corium and concrete compositions of past VULCANO test campaigns. 


\subsection{Concrete ablation ratio}

\subsubsection{Simulation code}

The concrete ablation ratio is represented as the values of $\Delta V / V$, where $\Delta V$ is the concrete ablation volume, and $V$ is the initial corium volume. The concrete ablation ratio of $1 \mathrm{~F}$ unit $1(1 \mathrm{~F} 1)$ was estimated with the MCCI simulation code: TOLBIAC-ICB, developed by CEA and IRSN [5].

In this study, stratification of the molten pool into oxide layer and metallic layer based on BALISE criteria is taken into consideration [6]. Conversely, water ingression into the surface crust and melt eruption from molten pool to water, which accelerate the cooling of molten pool, are not considered.

\subsubsection{Initial condition of $1 F 1$}

The MCCI, located in a sump pit in the pedestal, was simulated to understand the general characteristics of the MCCI product. The geometry of the sump pit is as follows: the base is a $1.4 \mathrm{~m}$ square and is $1.2 \mathrm{~m}$ deep. Because the geometry is symmetric to central face, a half unit was modeled in TOLBIAC-ICB.

The concrete composition was estimated from analytical results of the concrete sample picked up from 1F1 reactor building, as shown in Table 1 [7]. The molten core composition and mass in a sump pit were estimated by the mass of core internals and height of the molten core, as shown in Table 2 [8]. In this study, it was assumed that zircalloy is pure $\mathrm{Zr}$ and that half of all $\mathrm{Zr}$ was oxidized to $\mathrm{ZrO}_{2}$ before MCCI. The composition change of $\mathrm{UO}_{2}$ fuel by burn up and ex-vessel instrument material was not considered.

The decay heat of corium was estimated by using the data calculated with ORIGEN2 code [9]. In the case of $1 \mathrm{~F} 1$, it was estimated that the MCCI started $15 \mathrm{hrs}$ after the scram. It was assumed that $80 \%$ of the decay heat remains in the molten core due to a release of volatile fission products [8]. The decay heat of the molten core used in the calculation is as follows:

$$
P=457 \times 0.8 \times \exp \left(-2.611 \times 10^{-6} \times t\right)\left[\mathrm{kW} / \mathrm{m}^{3}\right]
$$

The initial corium temperature is defined as $2,873 \mathrm{~K}$, which is higher than the estimated melting temperature. The cooling water above the molten pool has been taken into consideration. The water temperature is set at $300 \mathrm{~K}$. The atmospheric pressure during MCCI is defined as $0.3 \mathrm{MPa}$.

Table 1. Estimated concrete composition of $1 \mathrm{~F} 1$ [wt \%]

\begin{tabular}{|c|c|c|c|c|c|}
\hline $\mathrm{SiO}_{2}$ & $\mathrm{CaCO}_{3}$ & $\mathrm{Ca}(\mathrm{OH})_{2}$ & $\mathrm{Al}_{2} \mathrm{O}_{3}$ & $\mathrm{Fe}_{2} \mathrm{O}_{3}$ & $\mathrm{H}_{2} \mathrm{O}$ \\
\hline 58 & 7 & 10 & 14 & 6 & 5 \\
\hline
\end{tabular}

Table 2. Estimated mass of the molten core in a sump pit [kg].

\begin{tabular}{|c|c|c|c|c|c|}
\hline $\mathrm{UO}_{2}$ & $\mathrm{Zr}$ & $\mathrm{ZrO}_{2}$ & $\mathrm{Fe}$ & $\mathrm{Cr}$ & $\mathrm{Ni}$ \\
\hline 8,000 & 1,600 & 2,200 & 1,280 & 300 & 220 \\
\hline
\end{tabular}

\subsubsection{Calculation results}

The calculated concrete ablation volume ratio is shown in Figure 2. The ablation volume ratio increases rapidly at the beginning of $\mathrm{MCCI}$, and then the slope becomes constant. One reason for this tendency is the decrease of molten pool temperature. The liquidus temperature of the molten pool composed of corium components decreases due to the mix of ablated concrete component. Subsequently, the molten pool temperature and concrete ablation rate decrease. Another reason for this phenomenon is the surplus heat derived from the gap between the input molten core temperature and the initial molten pool temperature which is slightly higher than the melting temperature. The surplus heat is distributed during initial $2.8 \mathrm{hrs}$. The calculated value of $\Delta V / V$ after $72 \mathrm{hrs}$ was 1.58 .

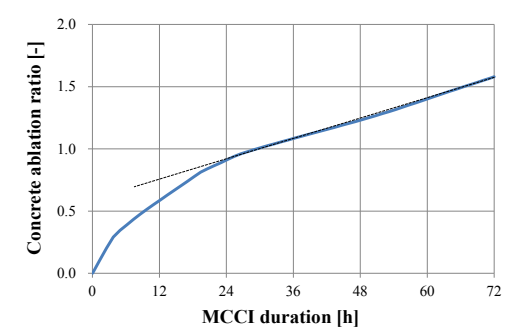

Figure 2. Calculated concrete ablation volume.

\subsection{Test campaign selection}

The value of $\Delta V / V$ of VBS-U4 was 1.62 , and this value was similar to the simulated value of $1 \mathrm{~F} 1$ after 72 hrs. Therefore, VBS-U4 was selected for sample analysis. The concrete composition and initial corium mass of VBS-U4 are shown in Tables 3 and 4 , respectively. The heating duration was $2.42 \mathrm{hr}$, and the initial corium temperature was $\sim 2150 \mathrm{~K}$.

Table 3. Concrete composition of VBS-U4 [wt\%].

\begin{tabular}{|c|c|c|c|c|c|}
\hline $\mathrm{SiO}_{2}$ & $\mathrm{CaO}$ & $\mathrm{Al}_{2} \mathrm{O}_{3}$ & $\mathrm{CO}_{2}$ & $\mathrm{H}_{2} \mathrm{O}$ & Others \\
\hline 63 & 16 & 5 & 9 & 3 & 4 \\
\hline
\end{tabular}

Table 4. Initial corium mass [kg].

\begin{tabular}{|c|c|c|c|c|c|}
\hline $\mathrm{UO}_{2}$ & $\mathrm{ZrO}_{2}$ & $\mathrm{SiO}_{2}$ & $\mathrm{FeO}_{\mathrm{x}}$ & $\mathrm{CaO}$ & $\mathrm{SUS}$ \\
\hline 15.8 & 6.8 & 6.9 & 5.4 & 0.2 & 24 \\
\hline
\end{tabular}

\section{Sample location and analytical method}

\subsection{Sample location}

Figure 3 presents an image of cross-sectional view of the VBS-U4 test section, as observed during the dismantling. In this test, four samples are chosen as representative of different locations. The approximate locations of four samples are shown in Figure 3.

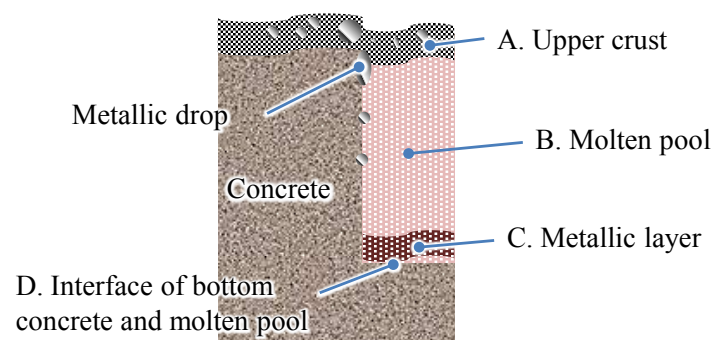

Figure 3. A cross-sectional view of the test section. 


\subsection{Analytical method}

The microstructural observation and elemental analysis of the samples are performed with a scanning electron microscope EVO HD15MA from Zeiss equipped with Energy Dispersive X-ray Spectroscopy (SEM-EDS) SDD X-Max 50 from Oxford Instruments. The cross sections to be analyzed were mirror polished.

The crystal structures contained in the samples were examined with X-ray diffraction (XRD) with a Bruker D2 diffractometer equipped with a Lynx Eye detector. Phase search was performed with the EVA software by using the International Centre for Diffraction Data (ICDD) database PDF-2 Release 2003.

The bulk density and apparent porosity were measured by international standard ISO 5017:2013.

Micro Vickers hardness of visually different phases in each sample was measured with an optical microscope. The load was 0.05-1 kgf.

\section{Results and discussion}

\subsection{Phase state, bulk density, and apparent porosity}

\subsubsection{Sample A: Upper crust}

Sample A is composed of three pieces as shown in Figure 4. The upper segment is metallic and other two segments are oxide. At the edges of the oxide segment, narrow concrete rich zones, indicated with blue dash lines, can be observed. Bubbles, which are confirmed as dark holes on the micrograph are present in both oxide segments, with sizes varying from $\sim 10 \mu \mathrm{m}$ up to 2.1 $\mathrm{mm}$.

The bulk density, $\rho_{b}$, and apparent porosity, $\pi_{a}$, are shown in Table 5. These values of sample A are relatively high compared to the other samples. It shows that this region was formed at an early stage of MCCI when the reaction generates a large amount of thermally decomposed gases of concrete, and the mixing of corium and concrete is small.

The microstructure of the edge of the metallic segments and the oxide segment at the micrometer scale is shown in Figure 4. The heterogeneous structure composed of several oxide phases derived from corium or concrete components is confirmed in the oxide segment. These phases would separately solidify in the liquidus corium rich nodule.

Table 5. Bulk density and apparent porosity.

\begin{tabular}{|c|c|c|c|c|c|}
\hline Samples & A & B & C & D1 & D2 \\
\hline$\rho_{b}\left[\mathrm{~g} / \mathrm{cm}^{3}\right]$ & 6.15 & 4.66 & 6.29 & 3.04 & 4.64 \\
\hline$\pi_{\mathrm{a}}[\%]$ & 22.26 & 9.91 & 5.72 & 2.71 & 18.06 \\
\hline
\end{tabular}

\subsubsection{Sample B: Molten pool}

The microstructure of sample B is shown in Figure 5. It can be confirmed that the corium rich region, which has a diameter of $1-20 \mathrm{~mm}$, is surrounded by concrete rich region at the millimeter scale. This shows a higher liquidus temperature of the corium rich region than concrete rich region and convection phenomena in molten pool during MCCI. Moreover, the heterogeneous microstructure composed of fcc-(U, $\mathrm{Zr}) \mathrm{O}_{2}, \mathrm{SiO}_{2}, \mathrm{Fe}-\mathrm{Cr}$, in corium rich region are confirmed at the micrometer scale. SUS was partially oxidized, and $\mathrm{Cr}$ formed $\mathrm{Cr}_{2} \mathrm{O}_{3}$. $\mathrm{SiO}_{2}$ forms amorphous and some crystalline phases, and it exhibits differences of localized cooling rate in the molten pool.
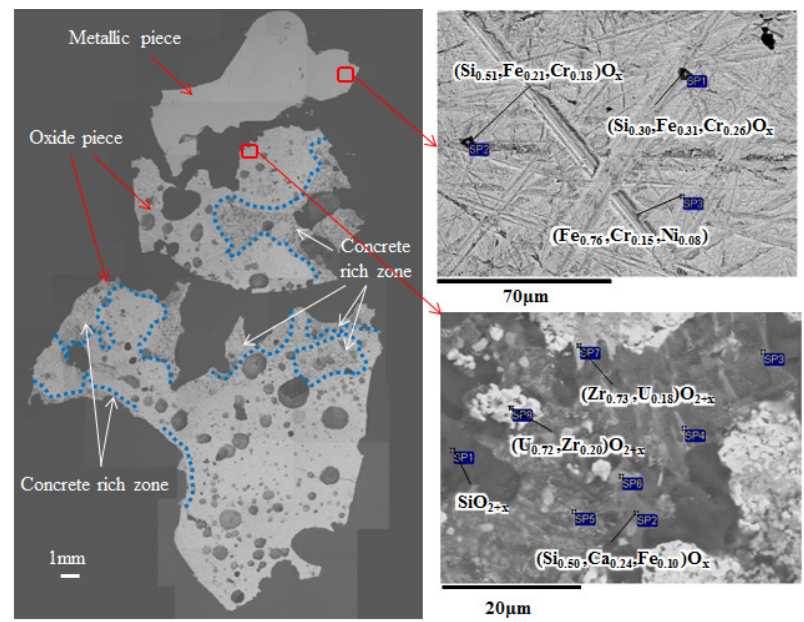

Figure 4. Microstructure of sample A.
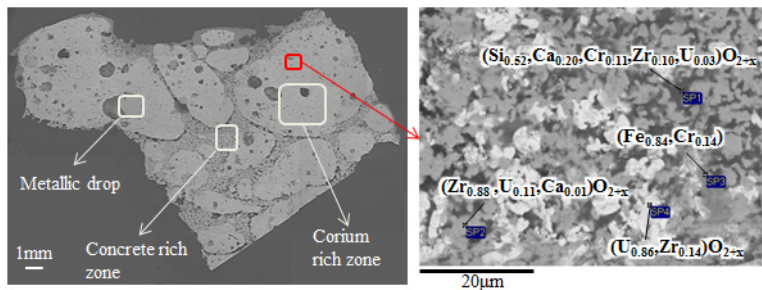

Figure 5. Microstructure of sample B.

\subsubsection{Sample C: Metallic piece}

A general view of the sample $\mathrm{C}$ at the millimeter scale is given in Figure 6. Sample $\mathrm{C}$ is a homogeneous and dense metallic block with small corium concrete mixture zones at its edges. The microstructure at the micrometer scale is also homogeneous and composed of $\alpha$-Fe containing $\mathrm{Cr}$ and $\mathrm{Ni}$. $\mathrm{Cr}$ is partially oxidized and the composition ratio is nearly constant in different locations. It shows that the oxidation reaction by concrete decomposition gases is a dominant reaction in this region and that the interaction with oxide corium phases would be small.
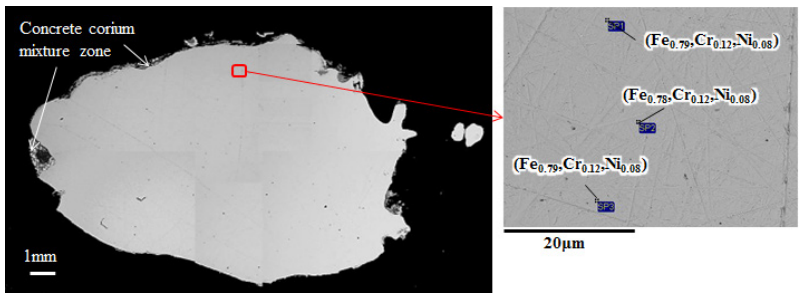

Figure 6. Microstructure of sample C.

\subsubsection{Sample D: Bottom concrete-molten pool interface}

The main segment of this sample at the millimeter scale is corium rich phase. Many aggregates derived from the concrete were detected in this phase. Moreover, 
many voids due to concrete thermal decomposition gases, with diameters more than $1 \mathrm{~mm}$, are distributed in left side of red dotted line. This shows that the convection of molten pool near concrete wall was small and the temperature during MCCI was relatively low. The microstructure at the micrometer scale is heterogeneous and composed of fcc-(U, Zr) $\mathrm{O}_{2}$; tet- $\mathrm{ZrO}$. $\mathrm{ZrSiO}_{4}$ was detected only in this sample due to relatively low temperature. The aggregates derived from the concrete are composed of oxides containing $\mathrm{Si}, \mathrm{Ca}$ and-Fe.

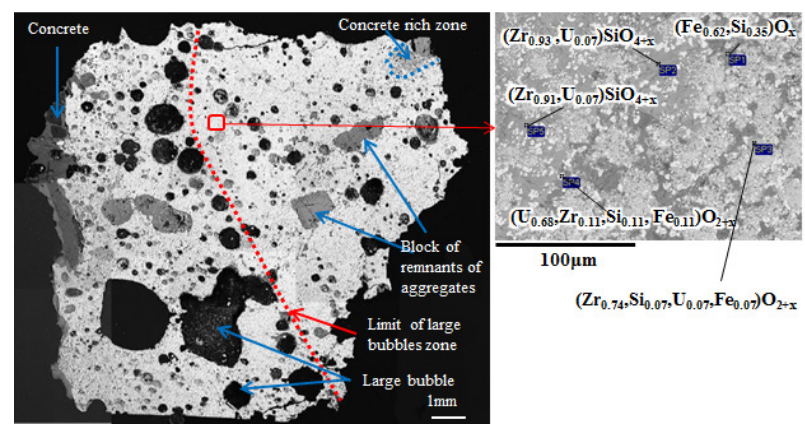

Figure 7. Microstructure of sample D.

\subsection{Vickers hardness}

Vickers hardness of 10-50 points, with respect to different phases, was measured in each sample. The average values of each phase are shown in Figure 8. The differences between the samples were minimal. In addition, the value of Vickers hardness between the same phases is similar. Vickers hardness of the metallic phase is relatively low and that of concrete rich phase is distributed to wide range. $\mathrm{U}$ or $\mathrm{Zr}$ rich phases and the concrete pure phase are relatively hard.

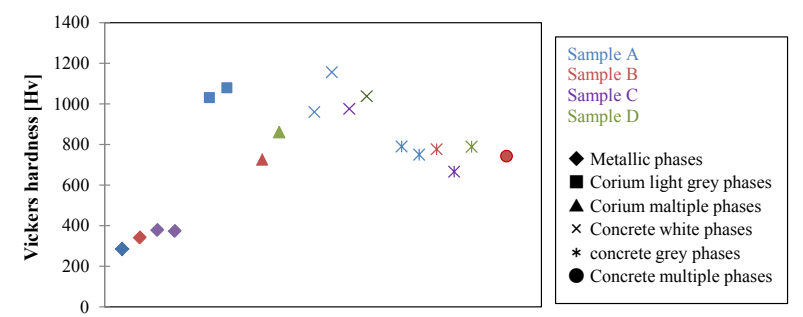

Figure 8. Vickers hardness of the samples.

\section{Conclusion}

The VULCANO MCCI test campaign, VBS-U4, was selected due to its similar conditions to $1 \mathrm{~F} 1 \mathrm{MCCI}$, and its test samples were analyzed. The macrostructure of the samples showed physicochemical phenomena during MCCI such as convection of molten pool and interaction between the molten core and the concrete. The microstructure of oxide region was heterogeneous, composed of several phases such as fcc-(U,Zr) $\mathrm{O}_{2}$, tet- $\mathrm{ZrO}_{2}, \mathrm{SiO}_{2}, \mathrm{Fe}-\mathrm{Si}-\mathrm{O}$, and $\mathrm{Fe}-\mathrm{Cr}$. The metallic region was homogeneous, mainly composed of $\mathrm{Fe}-\mathrm{Cr}-\mathrm{Ni}$ and partially oxidized. It was found that Vickers hardness depended less on the location and more on the chemical phases. Therefore, one of the main concerns about the use of mechanical removal tools is the difference of hardness between oxide and metallic phases and the distribution of these metallic phases in MCCI product.

\section{Acknowledgements}

VULCANO VBS-U4 test was performed by CEA in the frame of an agreement between CEA, EDF, IRSN, GDF-Suez, and SARNET. This study includes results obtained under the research program entrusted to the International Research Institute for Nuclear Decommissioning, including the Japan Atomic Energy Agency by the Agency for Natural Resources and Energy, Ministry of Economy, Trade and Industry (METI) of Japan.

\section{References}

[1] K. Yano, T. Kitagaki, H. Ikeuchi, R. Wakui, H. Higuchi, N. Kaji, K. Koizumi and T. Washiya, Direction on characterization of fuel debris for defueling process in Fukushima daiichi nuclear power plant, Proc. Int. Nucl. Fuel Cycle Conf. (GLOBAL2013), Salt Lake City, United States, Sept. 29-Oct. 3, 2013, (2013), pp. 1554-1559.

[2] B.R. Sehgal edit, Nuclear Safety in Light Water Reactors, Elsevier, Waltham, U.S., (2012) pp.307-424, ISBN 9780123884466.

[3] J.J. Foit, M. Fischer, C. Journeau and G. Langrock, Experiments on MCCI with oxide and steel, Ann. Nucl. Energy 74 (2014), pp. 100-109.

[4] C. Journeau, F. Sudreau, S. Magne and G. Cognet, Physico-chemical analyses and solidification path reconstruction of multi-component oxidic spread melts, Mater. Sci. Eng. A299 (2001), pp. 249-266.

[5] B. Spindler, B. Tourniaire and J.M. Seiler, Simulation of MCCI with the TOLBIAC-ICB code based on the phase segregation model, Nucl. Eng. Des. 236 (2006), pp. 2264-2270.

[6] B. Tourniaire and J.M. Bonnet, Study of the mixing of immiscible liquids by sparging gas results of the BALISE experiments, Proc. Int. Topical meet. Nucl. React. Therm. Hydaulics (NURETH-10), Seoul, Korea, Oct. 5-9, 2003, (2003).

[7] M. Ozawa, K. Yabuki, A. Shimada and T. Ueno, Chemical component analysis of core boring samples at reactor building in Fukushima-1 nuclear power plant, Proc. 2014 Annual Meeting of AESJ, Tokyo, Japan, Mar. 26-28, 2014, (2014) G35. [in Japanese]

[8] The Evaluation Status of Reactor Core Damage at Fukushima Daiichi Nuclear Power Station Units 1 to 3 [Internet], Tokyo Electric Power Company [cited 2017 Aug. 7], Tokyo, Japan, Available from: http://www.tepco.co.jp/nu/fukushimanp/images/ha handou_111130_09-j.pdf. [in Japanese]

[9] K. Nishihara, H. Iwamoto and K. Suyama, Estimation of fuel compositions in Fukushima-daiichi nuclear power plant, JAEA-Data/Code 2012-018, Japan Atomic Energy Agency, (2012). 